\title{
Clustering of patients with intrahepatic cholangiocarcinoma based on serum periostin may be predictive of prognosis
}

\author{
CHANITRA THUWAJIT ${ }^{1}$, PETI THUWAJIT ${ }^{1}$, PRANISA JAMJANTRA ${ }^{1}$, \\ CHAWALIT PAIROJKUL ${ }^{2}$, SOPIT WONGKHAM ${ }^{3}$, VAJARABHONGSA BHUDHISAWASDI ${ }^{4}$, \\ JUNYA ONO $^{5}$, SHOICHIRO OHTA $^{6}$, KIMINORI FUJIMOTO ${ }^{7}$ and KENJI IZUHARA $^{6}$ \\ ${ }^{1}$ Department of Immunology, Faculty of Medicine Siriraj Hospital, Mahidol University, Bangkok-Noi, Bangkok 10700; \\ Departments of ${ }^{2}$ Pathology, ${ }^{3}$ Biochemistry and ${ }^{4}$ Surgery, Faculty of Medicine, Khon Kaen University, Khon Kaen, \\ Khon Kaen 40002, Thailand; ${ }^{5}$ Research and Development Unit, Shino-Test Corporation, Minami-Ku, \\ Sagamihara, Kanagawa 252-0331; ${ }^{\circ}$ Department of Biomolecular Sciences, Saga Medical School, \\ Saga 849-8501; 7 Department of Radiology, Kurume University School of Medicine and Center for \\ Diagnostic Imaging, Kurume University Hospital, Kurume, Fukuoka 830-0011, Japan
}

Received January 4, 2016; Accepted March 3, 2017

DOI: $10.3892 / \mathrm{ol} .2017 .6250$

\begin{abstract}
An effective serum biomarker may improve cholangiocarcinoma (CCA) management. Periostin (PN) has been demonstrated to be associated with aggressive CCA. The current study evaluated PN in blood serum for its diagnostic and prognostic potential in patients with CCA. Sera of 68 patients with CCA were collected prior to treatment, and PN levels were measured using an ELISA. Sera from 50 normal controls, 6 patients with benign liver diseases, 2 with hepatocellular carcinoma and 21 with breast cancer were analyzed. Immunohistochemistry of PN in CCA tissues was also investigated. The data were analyzed using the Mann-Whitney $U$ test, Kaplan-Meier log rank tests, Cox proportional hazard regression models and Fisher's exact tests. The median serum PN level in patients with CCA was significantly increased compared with that in healthy controls, patients with benign liver diseases and patients with breast cancer (all $\mathrm{P}<0.05$ ). Using an optimal threshold value of $94 \mathrm{ng} / \mathrm{ml} \mathrm{PN}$, the diagnostic values for CCA compared with other conditions demonstrated a sensitivity level of 0.38 [95\% confidence interval (CI), 0.27-0.51], specificity of 0.90 (95\% CI, 0.81-0.96), accuracy of 0.66 (95\% CI, $0.58-0.74)$, positive predictive value of 0.76 (95\% CI, 0.59-0.89) and negative predictive value of 0.63 (95\% CI, 0.53-0.72) $(\mathrm{P}<0.001)$. Furthermore, PN stain in stromal fibroblasts in CCA tissues was associated with serum PN levels $(\mathrm{P}=0.001)$, and patients with $\mathrm{CCA}$ were classified
\end{abstract}

Correspondence to: Dr Chanitra Thuwajit, Department of Immunology, Faculty of Medicine Siriraj Hospital, Mahidol University, 2 Prannok Road, Bangkok-Noi, Bangkok 10700, Thailand E-mail: cthuwajit@yahoo.com

Key words: periostin, cholangiocarcinoma, serum marker, prognostic marker, fibroblasts as low ( $\leq 94 \mathrm{ng} / \mathrm{ml})$ or high PN (>94 ng/ml) accordingly. High serum and tissue PN levels were significantly associated with reduced survival rate $(\mathrm{P}<0.001$ and $\mathrm{P}=0.033$, respectively). Serum PN was an independent prognostic factor with a hazard ratio of $3.197(\mathrm{P}=0.001)$. In conclusion, serum $\mathrm{PN}$ may be used to divide patients with intrahepatic CCA into high and low PN groups. Elevated serum PN may be utilized as a marker of poor prognosis in patients with CCA.

\section{Introduction}

Cholangiocarcinoma (CCA) is a tumor consisting of bile duct epithelial cells, which is associated in Thailand with liver fluke disease (caused by Opisthorchis viverrini infection), and an important direct risk factor of this disease is inhabitation of the Opisthorchiasis endemic area in the northeastern part of the country (1). CCA is the major health problem in northeastern Khon Kaen province of Thailand, which has the highest incidence of liver fluke-induced CCA in the world (2-4). The prognosis of patients with CCA is poor, and the 3- and 5-year survival rate of patients with intrahepatic CCA following surgery is 21.7 and $11.2 \%$, respectively (5). This tumor demonstrates highly aggressive behavior, and is difficult to diagnose and to effectively predict its prognosis (6). Although serum carbohydrate antigen 19-9 (CA19-9) is currently the typical serum biomarker used for diagnosis in combination with other modalities, its sensitivity and specificity is low (7). In addition, it is not predictive of disease progression or prognosis. A novel serum marker as a prognostic marker is of increasing interest to be applied in CCA management.

As in other solid tumors including prostate (8), breast (9), non-small cell lung (10) and pancreatic cancer (11), the interaction between CCA cells and stromal cells in certain cancer-associated fibroblasts contribute to tumor development and progression of the disease. The fibroblasts isolated from fresh CCA tissues expressed alpha-smooth muscle cells, indicating that these fibroblasts were activated. The degree 
to which these fibroblasts are activated may be predictive of patient prognosis (12). These CCA-associated fibroblasts were demonstrated to have an abnormal gene expression profile compared with that of normal liver fibroblasts using a complementary DNA microarray (13). In a previous study, secreted tumor-promoting proteins were investigated, and it was identified that CCA-associated fibroblasts exhibited the capability of producing periostin ( $\mathrm{PN})$, an extracellular matrix protein, and the tissue level of PN was observed to be associated with patient survival (13). As PN has been demonstrated to be a multifunctional protein involved in the processes of carcinogenesis and progression $(14,15)$, previous in vitro CCA studies have suggested that PN has an important impact in cancer aggressiveness, as it induces a variety of tumorigenic properties, including cell proliferation, growth and invasion, partly via the integrin receptor $\alpha 5 \beta 1$ through the phosphatidylinositol-4,5-bisphosphate 3-kinase/AKT signaling pathway $(13,16)$.

PN has been identified in numerous cancer tissues, and it is produced primarily from cancer cells (17), stromal fibroblasts $(13,18)$ or both cell types $(19-23)$. Human epidermal growth factor receptor 2-positive and triple negative breast cancer tissue proteins were analyzed in a previous study, and the results demonstrated that $\mathrm{PN}$ was one of the proteins associated with tumor treatment response (17). In CCA, PN is expressed exclusively in tumor stromal fibroblasts $(13,18)$. Utispan et al detected expression of PN in fibroblasts but not in CCA or immune cells (13). By contrast, in hepatocellular carcinoma (HCC), a closely associated tumor to CCA, PN was observed at negative-to-low expression (13). Correlation analysis of PN levels and clinicopathological data suggested that tissue PN was an independent marker of poor prognosis in patients with CCA (13). PN was detected in epithelial cancer cells and stromal fibroblasts with a high incidence of PN-positive fibroblasts in $70 \%$ of total cases, compared with a lower PN-positive rate in cancer cells (20). The predominant expression of PN in epithelial cells was established in HCC, and was significantly associated with higher tumor grade and hepatitis B virus incidence, but not with overall survival rate (20). PN was associated with angiogenesis, and therefore, the combination of PN overexpression and microvascular invasion may be a marker of poor prognosis in patients with $\mathrm{HCC}(24,25)$. However, a significant impact of PN level in tissues on the overall survival time of patients with CCA was observed (13).

Using laser capture microdissection and reverse transcription-polymerase chain reaction, a previous study demonstrated that cancerous and stromal cells may be the source of PN production in non-small cell lung cancer (21). In prostate cancer, immunohistochemistry (IHC) analysis exhibited increased PN expression in carcinoma cells, which was associated with a high Gleason score and advanced tumor stage (19). Additionally, increased PN expression levels in tumor stroma were identified in the majority of primary and metastatic prostate cancer samples, leading to the conclusion that PN upregulation was associated with tumor aggressiveness in prostate cancer, and that it may be a potential target for therapeutic intervention (19). The medium and high level of stromal PN expression, compared with epithelial expression, independently predicted unfavorable prognosis in colorectal cancer (23). Additionally, the stromal PN expression increased consecutively from adjacent mucosa to primary tumor mass and metastatic colorectal cancer tissues (23). Taken together, these findings suggest that tissue $\mathrm{PN}$ is a potential molecular marker for diagnosis and prediction of prognosis, and a novel therapeutic target in numerous types of cancer, including CCA (26).

Serum PN level has been suggested as a diagnostic or prognostic marker in certain types of cancer, including non-small cell lung (27), colorectal (28), early-stage breast (29), breast with bone metastasis (30), ovarian (31), prostate (32), pancreatic (33), and head and neck squamous cell cancer (34). PN has been reported as a potential serodiagnostic marker in patients with CCA (35). In a previous study, a limited number of CCA cases were investigated, and serum PN, which was detected using an in-house established PN sandwich ELISA, which had been modified from a previous study (35) with the addition of a different antibody clone, was observed to be increased and able to distinguish patients with CCA from other associated conditions, particularly cirrhosis and HCC (35). The application of serum PN measurement to a large sample size of patients with CCA, however, remains to be investigated. In the present study, the use of an in-house established human PN ELISA to measure the sera PN in a large sample size of Thai patients with intrahepatic CCA was investigated, and compared with healthy controls and other associated and/or common malignancies. The serum and tissue PN levels and clinicopathological parameters were analyzed to indicate the potential of using circulating $\mathrm{PN}$ in serum for the diagnosis and prediction of prognosis in patients with CCA.

\section{Materials and methods}

Patients and tissues. In total 68 patients with CCA were enrolled on the study together with the patients from the control groups: 6 patients with benign liver diseases, including liver fibrosis, granulomatous liver, cholecystitis, obstructive bile ducts, biliary cystadenoma and cavernous hemangioma; 2 patients with $\mathrm{HCC} ; 21$ patients with breast cancer; and 50 control individuals (normal). All patients, with the exception of breast cancer patients, underwent surgery at the Faculty of Medicine, Khon Kaen University (Khon Kaen, Thailand) for standard treatment. The patients with breast cancer were admitted for treatment at Faculty of Medicine, Siriraj Hospital, Mahidol University (Bangkok, Thailand). Serum collection was approved by Khon Kaen Ethics Committee (EC no. 490143). The liver surgical specimen diagnoses were confirmed by pathologists according to the standard clinical guidelines. Patients with breast cancer had sera collected whilst they underwent surgery at the Faculty of Medicine Siriraj Hospital, Mahidol University (Bangkok, Thailand), under the protocol approval by Siriraj Institute Revision Board (si520/2010). Each patient was informed, and written informed consent was obtained. The sera were obtained prior to tumor mass removal and kept at $-80^{\circ} \mathrm{C}$ until used for experiments. The blood chemistry results of 50 normal controls that visited to the hospital for their yearly health check-up were used as the normal control in the present study. All 68 patients with CCA were used in experimental analyses regarding serum PN, whereas tissue PN was analyzed in only 66 cases, as there was an insufficient amount of tissues from 2 patients. 
ELISA for PN expression levels. Sera PN were measured using an established human PN sandwich ELISA as previously described (36-39). Briefly, $2 \mu \mathrm{g} / \mathrm{ml}$ rat SS18A IgG1 from the 'Periostin ELISA Kit (Human)' (Shino-Test Corporation, Tokyo, Japan) was incubated overnight at $25^{\circ} \mathrm{C}$ on ELISA plates (Loose MaxiSorp ${ }^{\circledR}$ Nunc-Immuno ${ }^{\circledR}$ Modules plates, Thermo Fisher Scientific, Inc., Waltham, MA, USA). The blocking buffer $(0.5 \%$ casein in $1 \mathrm{X}$ TBS, $\mathrm{pH} 8.0)$ was used to block non-specific binding by incubating the plates with the buffer overnight at $4^{\circ} \mathrm{C}$, and the tissue samples were then washed 3 times with washing buffer $(0.05 \%$ Tween-20 in $1 \mathrm{X}$ PBS). The ELISA plates were incubated with samples or 0-2 ng/ml recombinant PN standards derived from Drosophila $\mathrm{S} 2$ cells (40) (Shino-Test Corporation, Tokyo, Japan) for $18 \mathrm{~h}$ at $25^{\circ} \mathrm{C}$, followed by five washes. The peroxidase-labeled SS17B monoclonal antibody $(50 \mathrm{ng} / \mathrm{ml})$ sourced from the 'Periostin ELISA Kit (Human)' was added to $0.05 \%$ casein in TBS, followed by incubation for $90 \mathrm{~min}$ at $25^{\circ} \mathrm{C}$. Following washing of the ELISA plates with washing buffer, the reaction solution $\left(0.8 \mathrm{mM} \mathrm{3,3',5,5'-tetramethylbenzine,} 2.5 \mathrm{mM} \mathrm{H}_{2} \mathrm{O}_{2}\right)$ was added, followed by incubation for $10 \mathrm{~min}$ at $25^{\circ} \mathrm{C}$. The reactions were stopped by adding the stop solution $(0.7 \mathrm{~N} \mathrm{HCl})$ and incubating the plates at room temperature for $10 \mathrm{~min}$. The absorbance at $450 \mathrm{~nm}$ was measured within $60 \mathrm{~min}$ after the addition of the stop solution. The values were calculated simultaneously using the recombinant PN protein by subtraction of the absorbance at $550 \mathrm{~nm}$ from that of $450 \mathrm{~nm}$ ( $\Delta$ optical density) measured in the microplate reader (Bio-Rad Laboratories, Inc., Hercules, CA, USA). Each sample was performed in triplicate and the mean value was used.

IHC of PN in CCA tissues. In total, 66/68 cases of patients with CCA used for serum PN measurements were processed for paraffin embedding for PN detection using IHC. The tissue sections of 1-3 mm were fixed in $10 \%$ formaldehyde at room temperature for 1-3 h. The tissues were obtained from patients who underwent a hepatectomy using the protocol approved by the Human Research Ethics Committee of Khon Kaen University (EC no. 490143). The age, sex, tumor size, histological type and staging data were obtained from the medical and pathological records. Briefly, antigens were retrieved by incubating the paraffin-embedded tissues in $10 \mathrm{mM}$ citrate buffer $(\mathrm{pH} 6.0)$ at $95^{\circ} \mathrm{C}$ for $40 \mathrm{~min}$, and endogenous peroxidase was blocked by incubation with $3 \%$ $\mathrm{H}_{2} \mathrm{O}_{2}$ for $5 \mathrm{~min}$. Following blocking of non-specific binding with $2 \%$ bovine serum albumin (BSA, VWR International, Leicestershire, UK) for $20 \mathrm{~min}$ at room temperature, an in-house-developed rabbit anti-human PN (39) was applied to the sections at room temperature overnight at 1:10,000 dilution. The slides were then washed with $1 \mathrm{X}$ TBST (0.01\% Tween 20) washing buffer 3 times for $10 \mathrm{~min}$ followed by incubation with anti-rabbit EnVision+ System horseradish-peroxidase-labeled polymer (cat. no. K4003-11; dilution, ready to use; Dako; Agilent Technologies, Inc., Santa Clara, CA, USA) for $30 \mathrm{~min}$ at room temperature. The slides were then washed with $1 \mathrm{X}$ TBST $(0.01 \%$ Tween 20$)$ washing buffer for $10 \mathrm{~min} 3$ times. The immunoreactive signals were developed using 3,3'-diaminobenzidine (Sigma-Aldrich; Merck KGaA, Darmstadt, Germany). The tissues were washed with tap water for 5 min and counterstained with hematoxylin. The images were captured using a light microscope with magnification, x100.

PN expression in the fibroblasts was semi-quantitatively scored on the basis of PN-positive fibroblasts percentages and immunostaining intensity, as previously described (13). The interpretation of $\mathrm{PN}$ expression was performed by multiplying the scores of the percentage of positive cells (0-3) with the scores of staining intensity (1-3) to reach a total IHC score of $0-9$. The results were categorized as follows: Low expression, IHC score of $\leq 4$; and high expression, IHC score of $>4$. All tissue samples were anonymously and independently scored by two medical doctors (Dr Peti Thuwajit and Dr Chanitra Thuwajit). In case of disagreement, the slides were reexamined to obtain a consensus.

Statistical analysis. Data analysis was performed using the SPSS 18.0 statistical software package (SPSS, Inc., Chicago, IL, USA). The continuous data of serum PN levels were expressed as the median, including the first and third quartiles. Receiver operating characteristic (ROC) analyses were used to determine the threshold value of serum PN levels for distinguishing patients with CCA from patients with other diseases. The significance of the threshold value was evaluated for diagnostic performance using the sensitivity, specificity, accuracy, positive predictive value (PPV) and negative predictive value (NPV). The Mann-Whitney U test was performed to compare the PN level between different groups of patients. A survival analysis curve was calculated according to the Kaplan-Meier log rank test. Multivariate analysis for survival parameters was performed using the Cox proportional hazard regression model. The Fisher's exact test was used to analyze the correlation between parameters. $\mathrm{P}<0.05$ was considered to indicate a statistically significant difference.

\section{Results}

Serum $P N$ is increased in patients with CCA. Among the enrolled patients with CCA, $68 \%$ were male and $32 \%$ were female, equating to a ratio of 2:1 male: female (Table I). The median age for all patients in the present study was 56.5 years (range, 38-76 years). All the CCA cases were diagnosed as intrahepatic CCA, and the majority were pathologically classified as well-differentiated $(37 \%)$ or papillary $(57 \%)$ types.

Using a sandwich ELISA, recombinant human $\mathrm{PN}$ at a range of $0-2 \mathrm{ng} / \mathrm{ml}$ in $100 \mu \mathrm{l}$ diluent containing $50 \mathrm{mM}$ Tris- $\mathrm{HCl}$, $\mathrm{pH} 8.0,100 \mathrm{mM} \mathrm{NaCl}, 0-9 \% \mathrm{NaN}_{3}$ and $0.5 \%$ casein was used to create a standard curve for estimation of the concentration of PN in the patient sera (Fig. 1A). A linear curve was observed at a concentration of $\mathrm{PN} \leq 0.5 \mathrm{ng} / \mathrm{ml}$. The minimum detection limit of the ELISA was $20 \mathrm{pg} / \mathrm{ml}$. The median of serum PN was $52 \mathrm{ng} / \mathrm{ml}$ for patients with benign liver disease, whereas PN level was increased to $100 \mathrm{ng} / \mathrm{ml}$ in patients with $\mathrm{HCC}$ and $62 \mathrm{ng} / \mathrm{ml}$ in patients with breast cancer. Based on the Youden index, the optimal threshold value of serum PN level was $94 \mathrm{ng} / \mathrm{ml}$ (Fig. 1B). The ROC curve of serum PN in the comparison between patients with CCA and normal controls demonstrated that the area under the ROC curve was 0.608 , with a confidence interval (CI) of 0.509-0.706, and was statistically significant $(\mathrm{P}=0.043$; Fig. 1B). The overall serum $\mathrm{PN}$ level of the normal control patients had a median value 


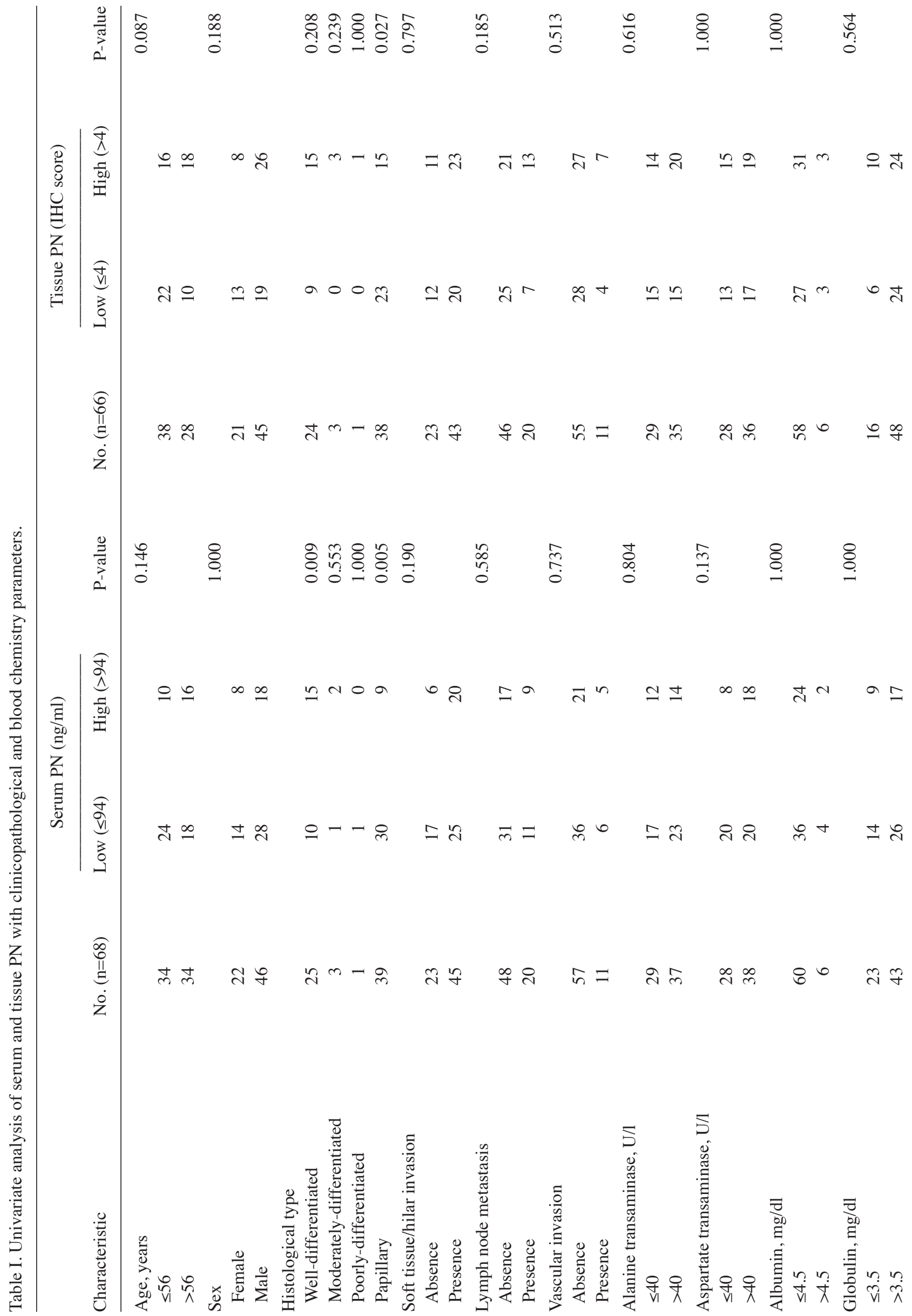


of $59 \mathrm{ng} / \mathrm{ml}$, which was lower compared with that of patients with CCA (median, $79 \mathrm{ng} / \mathrm{ml}$ ). The Mann-Whitney U test and Grubbs outlier test demonstrated significantly higher levels of serum PN in patients with CCA compared with those in normal controls ( $\mathrm{P}=0.041$; Fig. 1C).

The diagnostic performances for distinguishing CCA from other conditions, including benign liver diseases, HCC, breast cancer and healthy controls, reached statistically significant values for: Sensitivity, 0.38 (95\% CI, 0.27-0.51); specificity, 0.89 (95\% CI, 0.80-0.95); accuracy, 0.66 (95\% CI, 0.57-0.73); PPV, 0.74 (95\% CI, 0.57-0.88); and NPV, 0.63 (95\% CI, 0.53-0.72) (all P<0.001) (Table II). However, univariate analysis did not identify significant differences in serum PN or CA19-9, and therefore these may not be effective as potential diagnostic markers to identify CCA from benign conditions of the liver. The P-value of using $94 \mathrm{ng} / \mathrm{ml}$ serum $\mathrm{PN}$ as the threshold, $37 \mathrm{U} / \mathrm{ml}$ serum CA19-9 as the threshold and $94 \mathrm{ng} / \mathrm{ml}$ serum $\mathrm{PN}+37 \mathrm{U} / \mathrm{ml} \mathrm{CA} 19-9$ to distinguish CCA from benign liver diseases were $\mathrm{P}=0.406, \mathrm{P}=0.348$ and $\mathrm{P}=1.000$, respectively.

Serum $P N$ is associated with survival time of patients with $C C A$. There were no significant differences in serum PN levels according to age, gender, soft tissue/hilar invasion, lymph node metastasis or vascular invasion (Table I). The level of serum PN, however, was associated with well-differentiated CCA and papillary CCA, with P-values of $\mathrm{P}=0.009$ and $\mathrm{P}=0.005$, respectively. Notably, the present study demonstrated a significant association between serum $\mathrm{PN}$ and prothrombin time (PT) $(\mathrm{P}=0.032)$, whereas other blood chemistry parameters that represent liver functions were not significantly associated. In patients with CCA, serum with low PN was defined with the level of $\leq 94 \mathrm{ng} / \mathrm{ml}$, and $>94 \mathrm{ng} / \mathrm{ml}$ was defined as high PN. Multivariate analysis using Cox proportional hazard regression revealed the potential of high serum PN level as a factor of poor prognosis for CCA with statistical significance $(\mathrm{P}=0.001)$, whereas other parameters, including age, histological type, lymph node metastasis, vascular invasion and soft tissue/hilar invasion, were not significantly different (Table III). There were no cases of mortality in the current study within 2 weeks following surgery, and therefore, all 68 enrolled cases were used in the survival analysis. The results demonstrated that patients with a high serum PN level $(n=26)$ had a significant reduced survival rate (221.5 days) compared with that of patients with a low serum $\mathrm{PN}$ level $(\mathrm{n}=42 ; 612$ days; $\mathrm{P}<0.001$ (Fig. 1D). Using the 3 -year survival time as the threshold, the Kaplan-Meier log rank test demonstrated that serum PN levels may be used as a prognostic biomarker for poor survival rate in patients with CCA.

Level of serum PN is associated with tissue PN expression. The IHC results demonstrated that fibroblasts were the only source of PN expression in all histopathological types of CCA tissues (Fig. 2). In each histopathological type, PN was expressed at various levels, which were grouped into high (Fig. 2A, C and E) and low PN (Fig. 2B, D and F). Regarding the IHC score, the tissues with a score of $\leq 4$ were classified in the low PN group, whereas those with a score of $>4$ were placed in the high PN group. 


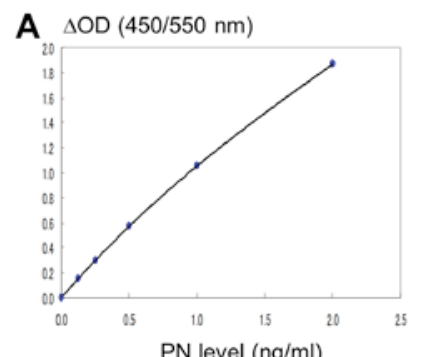

C

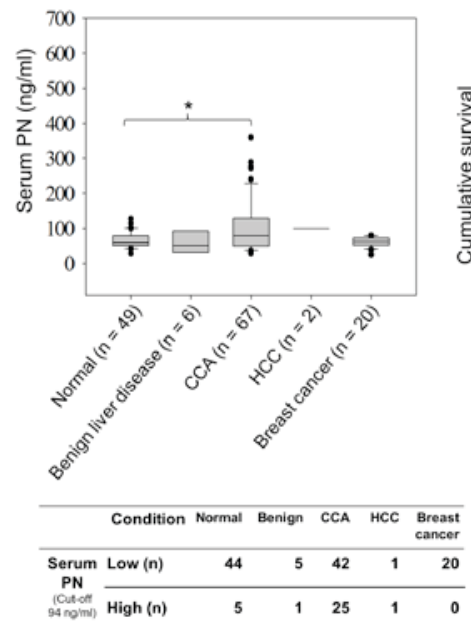

D
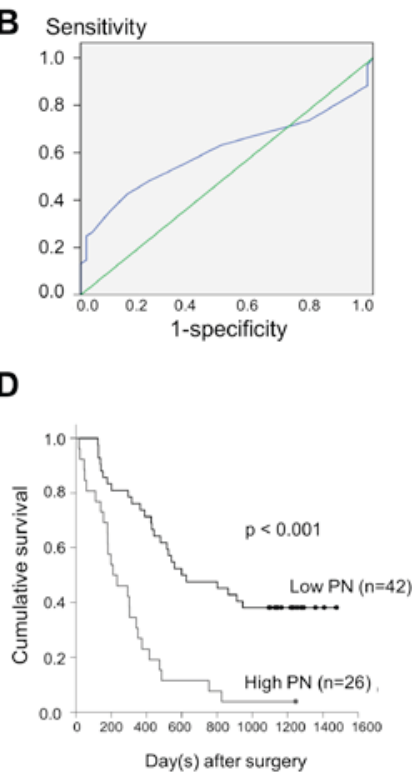

Figure 1. Serum PN measurement. (A) Standard curve of recombinant human $\mathrm{PN}$ in $\mathrm{ng} / \mathrm{ml}$. (B) Receiver operating characteristic curve for serum PN level to distinguish patients with CCA from normal controls. The area under the curve was 0.608 . The optimal threshold value between patients and healthy controls is $94 \mathrm{ng} / \mathrm{ml}$ (Youden's index, 0.266; $\mathrm{P}=0.043$ ). (C) Serum $\mathrm{PN}$ levels in normal volunteers and patients with benign liver disease, CCA and other malignancies, including HCC and breast cancer. The vertical bars indicate the range, while the horizontal boundaries of the boxes represent the standard deviation. Horizontal lines in the boxes represent median values. Statistical comparisons among multiple groups were performed using the Mann-Whitney U test. *, $\mathrm{P}=0.041$ (D) Survival analysis of patients with CCA and high or low levels of serum PN using Kaplan-Meier analysis. Using the 3-year survival rate, the cumulative survival of patients with high serum PN levels was significantly reduced compared with that of patients with low serum PN levels, according to the Mann-Whitney U test $(\mathrm{P}<0.001)$. PN, periostin; $\triangle \mathrm{OD}$, subtraction of the optical density, or absorbance, at $550 \mathrm{~nm}$ from that of $450 \mathrm{~nm}$; CCA, cholangiocarcinoma; HCC, hepatocellular carcinoma.

Tissue PN, as well as serum PN, was significantly associated with the papillary histopathological type $(\mathrm{P}=0.027)$ (Table I). There was no significant association of tissue PN with other clinicopathological parameters or blood chemistry parameters for liver function. Multivariate analysis revealed a significant association between tissue PN and soft tissue/hilar invasion $(\mathrm{P}=0.024)$ (Table III). Although the result identified that tissue PN may not be effective as an independent prognostic factor for poor survival, the Kaplan-Meier log rank test revealed a significant association between tissue $\mathrm{PN}$ and cumulative survival time ( $\mathrm{P}=0.033)$ (Fig. 2G). These results are concordant with patients with high tissue PN expression ( $\mathrm{n}=34$ ) having reduced survival rates (304 days) compared with those with low tissue $\mathrm{PN}$ expression $(\mathrm{n}=32$; 514 days) $(\mathrm{P}=0.038)$. The association of the number of low or high serum PN cases and the level of tissue PN is presented in Fig. 3 ( $\mathrm{P}=0.001)$. Using the Fisher's exact test, patients with high serum PN also frequently 


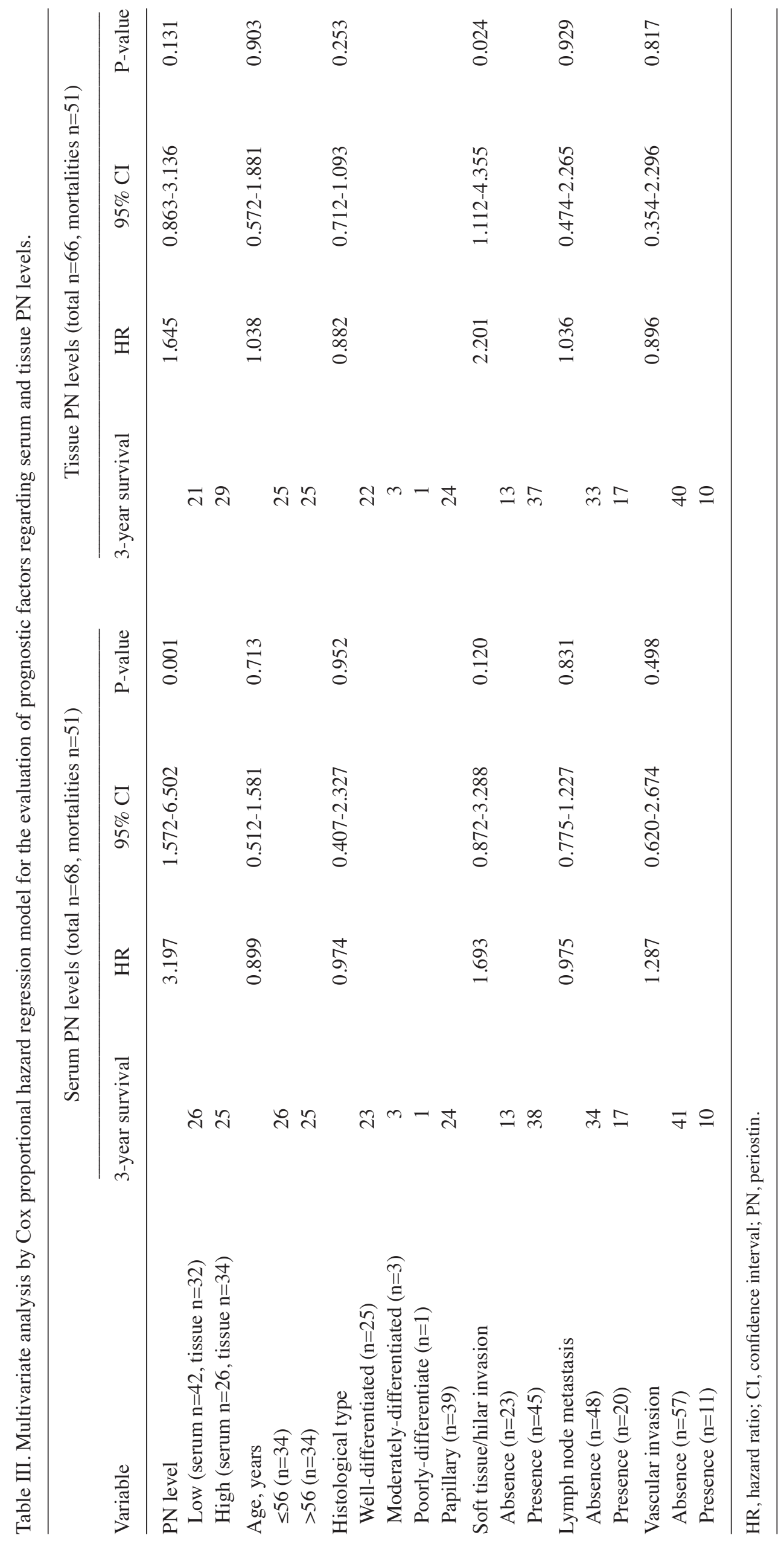



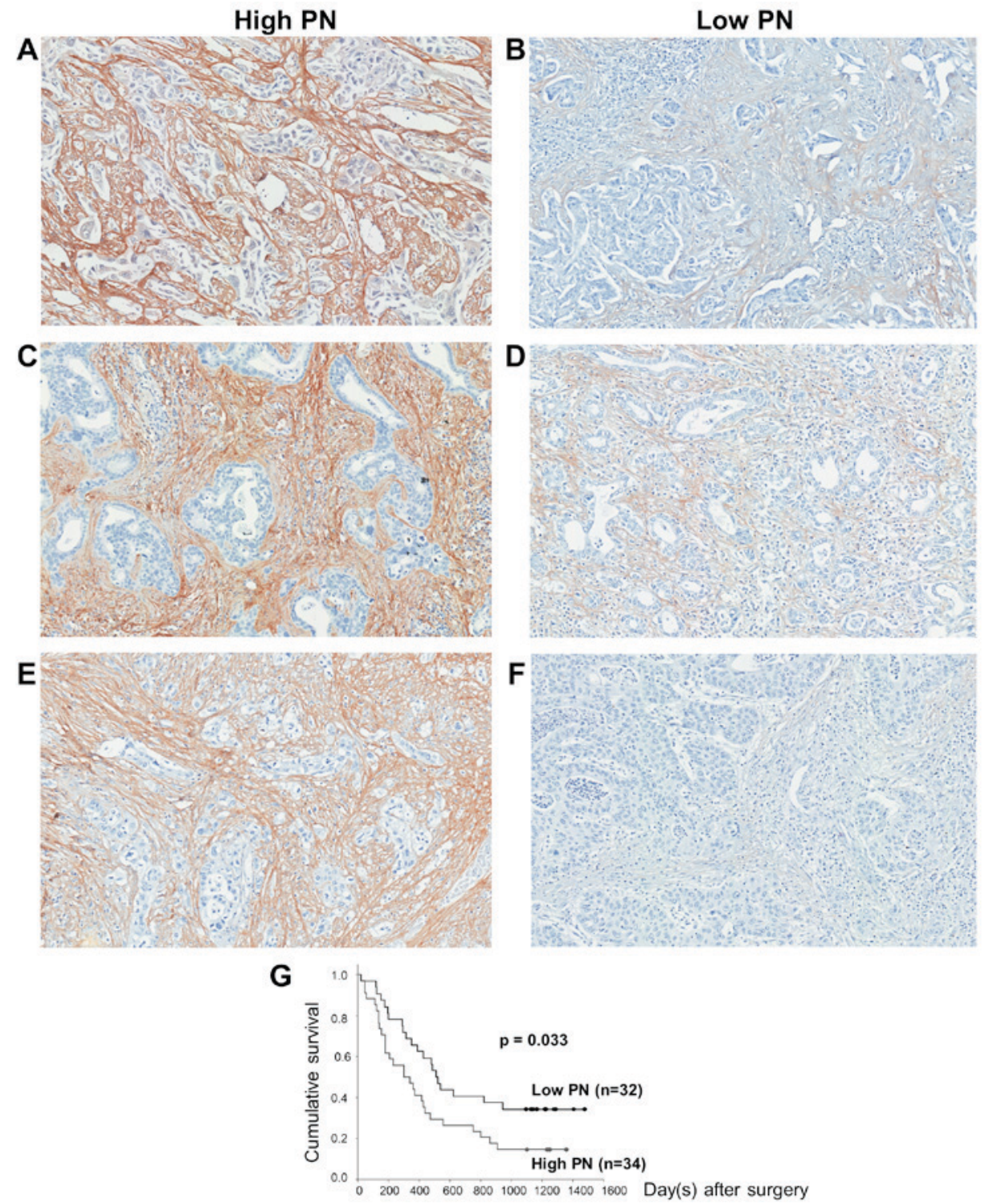

Figure 2. Immunohistochemical analysis of cholangiocarcinoma tissues with high or low PN expression levels and varying histopathological features. (A) Papillary histopathological type with high PN expression levels. (B) Papillary histopathological type with low PN expression levels. (C) Well-differentiated histopathological type with high PN expression levels. (D) Well-differentiated histopathological type with low PN expression levels. (E) Moderately-differentiated histopathological type with high PN expression levels. (F) Well-differentiated type with low PN expression levels. Magnification, x100. (G) The cumulative survival of patients with high tissue PN levels was significantly reduced compared with that of patients with low tissue $\mathrm{PN}$ levels $(\mathrm{P}=0.033)$. $\mathrm{PN}$, periostin.

exhibitedhightissue $\mathrm{PN}(\mathrm{P}=0.001)$ (Table IV).Similarly,patients with low serum PN were significantly associated with low tissue PN.

\section{Discussion}

The potential of using serum PN as a prognostic marker in patients with CCA was demonstrated in the present study. In concordance with previous studies that demonstrated that PN was exclusively located in CCA stromal fibroblasts in the patients' tissues $(13,20)$, PN was detected in patients' sera and utilized to classify patients into high or low serum PN groups. Notably, the high level of serum PN was significantly associated with a reduced survival rate following surgery in patients with CCA, which indicates the potential for serum PN to predict the aggressiveness of the disease.
The impact of PN on cancer cells leading to tumor progression has been established (15). A number of tumors have been identified to express high levels of PN in clinical specimens $(13,17,19,21)$. The expression of $\mathrm{PN}$ has been demonstrated to be induced by transforming growth factor-b (TGF- $\beta$ ) and bone morphogenetic protein (BMP)-2 $(41,42)$. In CCA, TGF- $\beta$ was expressed in cancer cells (43), and it is established that activated fibroblasts in cancer tissues may produce TGF- $\beta$ (44). Therefore, it may be possible that stromal fibroblasts are activated by cancer-derived or fibroblast-derived TGF- $\beta$ in a paracrine or autocrine manner, which leads to the activation of PN production from stromal cells into the tumor microenvironment. Although the reason for the observation of negative-to-low expression of PN in CCA cells has yet to be elucidated, it may be explained by the aberrant PN expression control machinery, particularly, the abnormalities of certain 
Table IV. Clustering of patients with high or low PN levels.

Serum PN expression, $\mathrm{ng} / \mathrm{ml}$

\begin{tabular}{lccc}
\cline { 2 - 3 } Variable & $\begin{array}{c}\text { Low, } \leq 94 \\
(\mathrm{n}=40)\end{array}$ & $\begin{array}{c}\text { High, }>94 \\
(\mathrm{n}=26)\end{array}$ & P-value \\
\hline Tissue PN, IHC score & & & 0.001 \\
High, $>4(\mathrm{n}=34)$ & 14 & 20 & \\
Low, $\leq 4(\mathrm{n}=32)$ & 26 & 6 & \\
\hline
\end{tabular}

PN, periostin; IHC, immunohistochemistry.

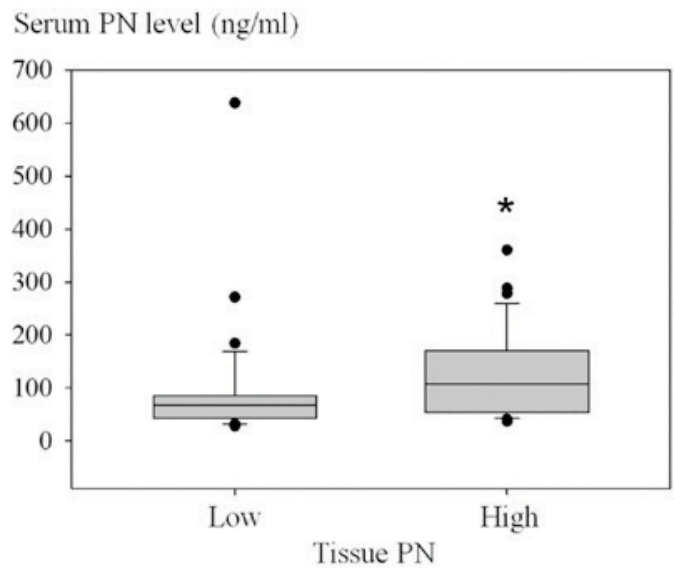

Figure 3. A graph demonstrating the association between serum and tissue $\mathrm{PN}$ levels in clinical cholangiocarcinoma tissues. The vertical bars indicate the range (10-90 percentile), while the horizontal boundaries of the boxes represent the standard deviation (25-75 percentile). Horizontal lines in the boxes represent median values. $\mathrm{PN}$, periostin. ${ }^{*}, \mathrm{P}=0.002$.

transcription factors $(45-47)$ and microRNAs (miRNAs) $(48,49)$. In addition, the high PN-expressing CCA-associated fibroblasts were identified to have low level of miR-1, whereas those with low PN had high miR-1 expression (unpublished data from our group). These results suggest the potential of miR-1 as a negative regulator of PN production in CCA-associated fibroblasts via blocking GATA- 6 and leading to the down-regulation of BMP-4, which normally activates PN expression (49). miR-1 has been reported to be able to regulate GATA-6, its targeted gene, which indirectly activates the expression of PN through the GATA-6 direct transcription target BMP-4 (49). Therefore, the reduction of miR-1 leads to the increased GATA- 6 that was observed in cells with PN overexpression. These results are in accordance with the previously described PN over-production from CCA stromal fibroblasts (13).

PN binds to the membrane receptor integrin $\alpha 5 \beta 1$ on CCA cells and activates cancer cell progression via the AKT signaling pathway to increase tumor aggressive properties, including cell proliferation, growth, migration and invasion $(13,16)$. Regarding $\mathrm{PN}$ as a secreted protein, serum PN has been detected in various types of activated stromal fibroblast-containing tumors, including non-small cell lung, colorectal, metastatic breast and ovarian cancer $(27,28,30,31)$. Notably, the majority of these tumors demonstrated that serum PN levels were associated with poor prognostic status of the diseases $(28,30)$. In CCA, serum PN was reported to be a diagnostic marker (35); however, the application of using serum PN as a prognostic marker has not been investigated thus far. The median serum PN level in 8 Japanese patients with CCA was $513 \mathrm{ng} / \mathrm{ml}$ (35), which is higher than that in the Thai patients with CCA evaluated in the present study $(79 \mathrm{ng} / \mathrm{ml})$. As serum PN levels in the blood samples in the above previous study (35) were investigated using a different ELISA kit (SS16A and SS17B; Shino-Test Corporation), the results cannot be directly compared with the PN values obtained in the present study. However, despite the modified ELISA kit (SS18A and SS17B) used on the sera samples analyzed in the present study that contained a different clone of the anti-PN antibody, the median PN values in the tissue samples was $230 \mathrm{ng} / \mathrm{ml}$ (unpublished data), which was higher than that detected in the present study. This discrepancy may be attributed to differences in the genetic background between Thai and Japanese populations, tumor size, tumor invasiveness and/or the etiological causes of CCA. However, the primary result is the identification of increased serum PN levels in patients with CCA compared with those in patients with other conditions.

Serum PN is positively associated with liver enzymes and proteins (aspartate transaminase, alanine transaminase, alkaline phosphatase and total albumin) and liver stiffness, but negatively associated with serum albumin in patients with post-operative biliary atresia (50). This previous study concluded that serum PN was associated with hepatic dysfunction, liver fibrosis and jaundice status (50). The univariate analysis conducted in the present study demonstrated that serum PN was significantly associated with PT. The majority of patients with CCA and normal PT had low serum PN, whilst a large number of patients with high serum PN had prolonged PT. This may be explained by the liver dysfunction and PN overexpression observed in patients with CCA. Regarding the histological type, papillary CCA has been established to be associated with good prognosis, and concordant with this, the rate of liver metastasis has been identified to be significantly higher for intraductal CCA with a tubular growth pattern than for CCA with a papillary growth pattern (51). Therefore, the results of the current study indicated that the low PN levels in serum and tissue were significantly associated with papillary CCA and are of clinical importance. However, the significant association of serum PN, unlike tissue PN, with well-differentiated CCA may be statistically significant, but not biologically significant.

Although IHC has previously demonstrated that breast cancer exhibits an increased PN expression level (52), no significant increase in the level of serum PN was observed in the current study. This may be due to the area of cancer cells and/or stromal fibroblasts being identified as the source of PN in breast cancer compared with that in CCA, which is smaller and may not have this caveat. These previous data are concordant with the results of the present study that the serum PN levels in patients with breast cancer, of which none had metastatic disease, were not significantly increased compared with those in the normal controls. In the metastatic cases, breast cancer cells that have settled in the bone marrow stroma may activate the stromal and bone cells to support the growth of metastatic cancer cells through bone-derived factors, including TGF- $\beta$ and BMPs (53). These secreted substances 
may then activate cancer cells and/or stromal fibroblasts to produce $\mathrm{PN}$ and release this into the blood circulation. In HCC tissues, the fibrous capsule surrounding the cancer cells was mildly stained for PN $(13,35)$. In the present study, serum $\mathrm{PN}$ in patients with HCC exhibited a higher level compared with that in patients with CCA, which is opposed to the findings of Fujimoto et al (35). However, increased serum PN in patients with HCC compared with that in normal controls and benign liver diseases was supported by Lv et al (54). Serum markers, including alpha-fetoprotein and CA19-9, may be used for early detection of liver and bile duct cancer but only have moderate sensitivity and specificity (55). When using the $94 \mathrm{ng} / \mathrm{ml}$ threshold value to distinguish patients with CCA from patients with other conditions, the results of the present study demonstrated that the diagnostic performance was statistically significant with high specificity, even though the sensitivity was low. The specificity of serum PN in the present study was higher compared with that reported for CA19-9 (7); however, the sensitivity of the two serum markers was low. Therefore, it is not remarkable that using serum PN to distinguish CCA from benign liver diseases was not statistically significant. This result from the present study may suggest that serum PN is specific to CCA, but using it to detect early CCA may not be effective. This conclusion is similar to that regarding serum CA19-9 that was summarized in a guideline, which reported CA19-9 to be insufficient to establish the diagnosis of CCA (56). In the current study, the combination of serum PN and CA19-9 did not add value to the diagnostic potential of differentiating CCA from benign liver diseases. Novel biomarkers, including the soluble fragment of cytokeratin 19 (CYFRA 21-1), mucins, pyruvate kinase and certain metalloproteinases, including matrix metalloproteinase 7 , have been reported to aid in the diagnosis of $\mathrm{CCA}$, and in certain cases, also act to establish prognostic values (57). However, none of these biomarkers are part of current routine clinical practice.

The increased PN level in the serum of patients with CCA was associated with increased PN expression levels in CCA-associated fibroblasts. The fibroblast-derived PN may not only act on cancer cells locally to activate the tumorigenic properties, leading to cancer aggressiveness and reduced survival rate (13), but also may be secreted into the blood circulation. Notably, the results of the present study supported that the serum and tissue PN levels may be used to divide patients with CCA into high and low PN groups. In addition to a previous study that demonstrated that tissue PN level was significantly associated with reduced patient survival time (13), high serum PN in the current study was associated with reduced cumulative survival of patients with CCA. Therefore, serum PN may be applied as a marker of poor prognosis to predict the aggressiveness of the disease. Serum CA19-9 was analyzed in the present study, and did not exhibit an association with survival rates (data not shown). This is in contrast to the previously reported recommendation that CA19-9 may be of prognostic significance in CCA (56). This may be explained by the varying CA19-9 threshold level used in the previous studies $(56,58)$ and in the present study. Carcinoembryonic antigen (CEA) is another serum tumor marker that is used in CCA management and has been identified, together with lymph node metastasis, to be associated with advanced stage tumors and negative prognostic factors in CCA (59). Notably, the results of the present study indicate that the statistical impact of serum PN as a prognostic marker appears to be an improvement upon serum CEA.

In conclusion, the current study suggests that the impact of serum PN exclusively produced in CCA cancer-associated fibroblasts may be used as a validated predictive marker for patient survival. Although certain stromal substances produced from cancer cells or cancer-associated fibroblasts have been investigated using IHC for their increased levels and proposed as a prognostic marker in intrahepatic CCA, including PN (13), osteopontin, laminin and TGF- $\beta 2$ (60), the current study has demonstrated that $\mathrm{PN}$ is a substance that is detectable in patients' serum and able to predict the aggressiveness of the disease. Patients with high serum PN levels at the time of diagnosis may be considered to require aggressive adjuvant treatment. Although a well-designed study, in which extensive patient follow-up and regular testing of blood samples from the patients, to investigate patients with CCA following surgery is required to inform further, it can be suggested that serum PN is an effective indicative marker for treatment responsiveness and tumor recurrence.

\section{Acknowledgements}

The English editing of the present manuscript was kindly performed by Professor James A. Will (University of Wisconsin, Madison, WI, USA). The present study has been supported by a research grant from Thailand Research Fund (grant no. RSA5480003) awarded to Dr Chanitra Thuwajit, and a grant from the Faculty of Medicine Siriraj Hospital, Mahidol University (Bangkok, Thailand).

Professor Kenji Izuhara has received >2,000,000 Japanese Yen from Shino-Test Corporation (Kanagawa, Japan) as research funding.

\section{References}

1. Sithithaworn P, Andrews RH, Nguyen VD, Wongsaroj T, Sinuon M, Odermatt P, Nawa Y, Liang S, Brindley PJ and Sripa B: The current status of opisthorchiasis and clonorchiasis in the Mekong Basin. Parasitol Int 61: 10-16, 2012.

2. Shin HR, Oh JK, Masuyer E, Curado MP, Bouvard V, Fang YY, Wiangnon S, Sripa B and Hong ST: Epidemiology of cholangiocarcinoma: An update focusing on risk factors. Cancer Sci 101: 579-585, 2010.

3. Vatanasapt V, Uttaravichien T, Mairiang EO, Pairojkul C, Chartbanchachai W and Haswell-Elkins M: Cholangiocarcinoma in north-east Thailand. Lancet 335: 116-117, 1990

4. Sripa B, Brindley PJ, Mulvenna J, Laha T, Smout MJ, Mairiang E, Bethony JM and Loukas A: The tumorigenic liver fluke Opisthorchis viverrini-multiple pathways to cancer. Trends Parasitol 28: 395-407, 2012.

5. Sriputtha S, Khuntikeo N, Promthet S and Kamsa-Ard S: Survival rate of intrahepatic cholangiocarcinoma patients after surgical treatment in Thailand. Asian Pac J Cancer Prev 14: 1107-1110, 2013.

6. Khan SA, Miras A, Pelling M and Taylor-Robinson SD: Cholangiocarcinoma and its management. Gut 56: 1755-1756, 2007.

7. Khan SA, Davidson BR, Goldin RD, Heaton N, Karani J, Pereira SP, Rosenberg WM, Tait P, Taylor-Robinson SD, Thillainayagam $\mathrm{AV}$, et al: Guidelines for the diagnosis and treatment of cholangiocarcinoma: An update. Gut 61: 1657-1669, 2012.

8. Franco OE and Hayward SW: Targeting the tumor stroma as a novel therapeutic approach for prostate cancer. Adv Pharmacol 65: 267-313, 2012.

9. Hasebe T: Tumor-stromal interactions in breast tumor progression-significance of histological heterogeneity of tumor-stromal fibroblasts. Expert Opin Ther Targets 17: 449-460, 2013. 
10. Bremnes RM, Donnem T, Al-Saad S, Al-Shibli K, Andersen S, Sirera R, Camps C, Marinez I and Busund LT: The role of tumor stroma in cancer progression and prognosis: Emphasis on carcinoma-associated fibroblasts and non-small cell lung cancer J Thorac Oncol 6: 209-217, 2011.

11. Spector I, Zilberstein Y, Lavy A, Nagler A, Genin O and Pines M: Involvement of host stroma cells and tissue fibrosis in pancreatic tumor development in transgenic mice. PLoS One 7: e 41833, 2012

12. Chuaysri C, Thuwajit P, Paupairoj A, Chau-In S, Suthiphongchai $T$ and Thuwajit $C$ : Alpha-smooth muscle actin-positive fibroblasts promote biliary cell proliferation and correlate with poor survival in cholangiocarcinoma. Oncol Rep 21: 957-969, 2009.

13. Utispan K, Thuwajit P, Abiko Y, Charngkaew K, Paupairoj A Chau-in S and Thuwajit C: Gene expression profiling of cholangiocarcinoma-derived fibroblast reveals alterations related to tumor progression and indicates periostin as a poor prognostic marker. Mol Cancer 9: 13, 2010

14. Ratajczak-Wielgomas K and Dziegiel P: The role of periostin in neoplastic processes. Folia Histochem Cytobiol 53: 120-132, 2015.

15. Ruan K, Bao S and Ouyang G: The multifaceted role of periostin in tumorigenesis. Cell Mol Life Sci 66: 2219-2230, 2009.

16. Utispan K, Sonongbua J, Thuwajit P, Chau-In S, Pairojkul C, Wongkham $S$ and Thuwajit C: Periostin activates integrin $\alpha 5 \beta 1$ through a PI3K/AKT-dependent pathway in invasion of cholangiocarcinoma. Int J Oncol 41: 1110-1118, 2012.

17. He J, Whelan SA, Lu M, Shen D, Chung DU, Saxton RE, Faull KF, Whitelegge JP and Chang HR: Proteomic-based biosignatures in breast cancer classification and prediction of therapeutic response. Int J Proteomics 2011: 896476, 2011.

18. Dumur CI, Campbell DJ, DeWitt JL, Oyesanya RA and Sirica AE: Differential gene expression profiling of cultured neu-transformed versus spontaneously-transformed rat cholangiocytes and of corresponding cholangiocarcinomas. Exp Mol Pathol 89: 227-235, 2010.

19. Tischler V, Fritzsche FR, Wild PJ, Stephan C, Seifert HH, Riener MO, Hermanns T, Mortezavi A, Gerhardt J, Schraml P, et al: Periostin is up-regulated in high grade and high stage prostate cancer. BMC Cancer 10: 273, 2010.

20. Riener MO,Fritzsche FR, Soll C, Pestalozzi BC, Probst-Hensch N, Clavien PA, Jochum W, Soltermann A, Moch H and Kristiansen G: Expression of the extracellular matrix protein periostin in liver tumours and bile duct carcinomas. Histopathology 56: 600-606, 2010.

21. Morra L, Rechsteiner M, Casagrande S, von Teichman A, Schraml P, Moch H and Soltermann A: Characterization of periostin isoform pattern in non-small cell lung cancer. Lung Cancer 76: 183-190, 2012

22. Wang H, Wang Y and Jiang C: Stromal protein periostin identified as a progression associated and prognostic biomarker in glioma via inducing an invasive and proliferative phenotype. Int J Oncol 42: 1716-1724, 2013

23. Xu X, Chang W, Yuan J, Han X, Tan X, Ding Y, Luo Y, Cai H, Liu Y, Gao X, et al: Periostin expression in intra-tumoral stromal cells is prognostic and predictive for colorectal carcinoma via creating a cancer-supportive niche. Oncotarget 7: 798-813, 2016.

24. Lv Y, Wang W, Jia WD, Sun QK, Li JS, Ma JL, Liu WB, Zhou HC, Ge YS, Yu JH, et al: High-level expression of periostin is closely related to metastatic potential and poor prognosis of hepatocellular carcinoma. Med Oncol 30: 385, 2013.

25. Jang SY, Park SY, Lee HW, Choi YK, Park KG, Yoon GS Tak WY, Kweon YO, Hur K and Lee WK: The Combination of Periostin Overexpression and Microvascular Invasion Is Related to a Poor Prognosis for Hepatocellular Carcinoma. Gut Liver 10: 948-954, 2016

26. Sirica AE, Almenara JA and Li C: Periostin in intrahepatic cholangiocarcinoma: Pathobiological insights and clinical implications. Exp Mol Pathol 97: 515-524, 2014.

27. Hong L, Sun H, Lv X, Yang D, Zhang J and Shi Y: Expression of periostin in the serum of NSCLC and its function on proliferation and migration of human lung adenocarcinoma cell line (A549) in vitro. Mol Biol Rep 37: 2285-2293, 2010.

28. Ben QW, Zhao Z, Ge SF, Zhou J, Yuan F and Yuan YZ: Circulating levels of periostin may help identify patients with more aggressive colorectal cancer. Int J Oncol 34: 821-828, 2009.

29. Nuzzo PV, Rubagotti A, Argellati F, Di Meglio A, Zanardi E, Zinoli L, Comite P, Mussap M and Boccardo F: Prognostic value of preoperative serum levels of periostin (PN) in early breast cancer (BCa). Int J Mol Sci 16: 17181-17192, 2015.
30. Contie S, Voorzanger-Rousselot N, Litvin J, Clézardin P and Garnero P: Increased expression and serum levels of the stromal cell-secreted protein periostin in breast cancer bone metastases. Int J Cancer 128: 352-360, 2011.

31. Abbott KL, Lim JM, Wells L, Benigno BB, McDonald JF and Pierce $\mathrm{M}$ : Identification of candidate biomarkers with cancer-specific glycosylation in the tissue and serum of endometrioid ovarian cancer patients by glycoproteomic analysis. Proteomics 10: 470-481, 2010.

32. Capoun O, Soukup V, Kalousová M, Sobotka R, Pešl M, Zima T and Hanuš T: Diagnostic importance of selected protein serum markers in the primary diagnostics of prostate cancer. Urol Int 95: 429-435, 2015

33. Liu Y and Du L: Role of pancreatic stellate cells and periostin in pancreatic cancer progression. Tumour Biol 36: 3171-3177, 2015.

34. Kudo Y, Iizuka S, Yoshida M, Nguyen PT, Siriwardena SB, Tsunematsu T, Ohbayashi M, Ando T, Hatakeyama D and Shibata T: Periostin directly and indirectly promotes tumor lymphangiogenesis of head and neck cancer. PLoS One 7: e44488, 2012.

35. Fujimoto K, Kawaguchi T, Nakashima O, Ono J, Ohta S, Kawaguchi A, Tonan T, Ohshima K, Yano $\mathrm{H}$, Hayabuchi $\mathrm{N}$, et al: Periostin, a matrix protein, has potential as a novel serodiagnostic marker for cholangiocarcinoma. Oncol Rep 25: 1211-1216, 2011

36. Okamoto M, Hoshino T, Kitasato Y, Sakazaki Y, Kawayama T, Fujimoto K, Ohshima K, Shiraishi H, Uchida M, Ono J, et al: Periostin, a matrix protein, is a novel biomarker for idiopathic interstitial pneumonias. Eur Respir J 37: 1119-1127, 2011.

37. Masuoka M, Shiraishi H, Ohta S, Suzuki S, Arima K, Aoki S, Toda S, Inagaki N, Kurihara Y, Hayashida S, et al: Periostin promotes chronic allergic inflammation in response to Th2 cytokines. J Clin Invest 122: 2590-2600, 2012.

38. Kanemitsu Y, Matsumoto H, Izuhara K, Tohda Y, Kita H, Horiguchi T, Kuwabara K, Tomii K, Otsuka K, Fujimura M, et al: Increased periostin associates with greater airflow limitation in patients receiving inhaled corticosteroids. J Allergy Clin Immunol 132: 305-12 e3, 2013

39. Yamaguchi Y, Ono J, Masuoka M, Ohta S, Izuhara K, Ikezawa Z, Aihara M and Takahashi K: Serum periostin levels are correlated with progressive skin sclerosis in patients with systemic sclerosis. Br J Dermatol 168: 717-725, 2013.

40. Takayama G, Arima K, Kanaji T, Toda S, Tanaka H, Shoji S, McKenzie AN, Nagai H, Hotokebuchi T and Izuhara K: Periostin: A novel component of subepithelial fibrosis of bronchial asthma downstream of IL-4 and IL-13 signals. J Allergy Clin Immunol 118: 98-104, 2006

41. Horiuchi K, Amizuka N, Takeshita S, Takamatsu H, Katsuura M, Ozawa H, Toyama Y, Bonewald LF and Kudo A: Identification and characterization of a novel protein, periostin, with restricted expression to periosteum and periodontal ligament and increased expression by transforming growth factor beta. J Bone Miner Res 14: 1239-1249, 1999.

42. Inai K, Norris RA, Hoffman S, Markwald RR and Sugi Y: BMP-2 induces cell migration and periostin expression during atrioventricular valvulogenesis. Dev Biol 315: 383-396, 2008.

43. Ohira S, Itatsu K, Sasaki M, Harada K, Sato Y, Zen Y, Ishikawa A, Oda K, Nagasaka T, Nimura Y and Nakanuma Y: Local balance of transforming growth factor-betal secreted from cholangiocarcinoma cells and stromal-derived factor- 1 secreted from stromal fibroblasts is a factor involved in invasion of cholangiocarcinoma. Pathol Int 56: 381-389, 2006

44. Lu JP, Mao JQ, Li MS, Lu SL, Hu XQ, Zhu SN and Nomura S: In situ detection of TGF betas, TGF beta receptor II mRNA and telomerase activity in rat cholangiocarcinogenesis. World J Gastroenterol 9: 590-594, 2003.

45. Puppin C, Passon N, Frasca F, Vigneri R, Tomay F, Tomaciello S and Damante G: In thyroid cancer cell lines expression of periostin gene is controlled by p73 and is not related to epigenetic marks of active transcription. Cell Oncol (Dordr) 34: 131-140, 2011.

46. Oshima A, Tanabe H, Yan T, Lowe GN, Glackin CA and Kudo A: A novel mechanism for the regulation of osteoblast differentiation: Transcription of periostin, a member of the fasciclin I family, is regulated by the bHLH transcription factor, twist. J Cell Biochem 86: 792-804, 2002

47. Romeo F, Falbo L, Di Sanzo M, Misaggi R, Faniello MC, Barni T, Cuda G, Viglietto G, Santoro C, Quaresima B and Costanzo F: Negative transcriptional regulation of the human periostin gene by YingYang-1 transcription factor. Gene 487: 129-134, 2011 
48. Zinn PO, Mahajan B, Sathyan P, Singh SK, Majumder S, Jolesz FA and Colen RR: Radiogenomic mapping of edema/cellular invasion MRI-phenotypes in glioblastoma multiforme. PLoS One 6: e25451, 2011

49. Niu Z, Iyer D, Conway SJ, Martin JF, Ivey K, Srivastava D, Nordheim A and Schwartz RJ: Serum response factor orchestrates nascent sarcomerogenesis and silences the biomineralization gene program in the heart. Proc Natl Acad Sci USA 105: 17824-17829, 2008.

50. Honsawek S, Udomsinprasert W, Vejchapipat $\mathrm{P}$, Chongsrisawat $\mathrm{V}$, Phavichitr N and Poovorawan Y: Elevated serum periostin is associated with liver stiffness and clinical outcome in biliary atresia. Biomarkers 20: 157-161, 2015.

51. Tsukahara T, Shimoyama Y, Ebata T, Yokoyama Y, Igami T, Sugawara G, Mizuno T, Yamaguchi J, Nakamura S and Nagino M Cholangiocarcinoma with intraductal tubular growth pattern versus intraductal papillary growth pattern. Mod Pathol 29: 293-301, 2016.

52. Kharaishvili G, Cizkova M, Bouchalova K, Mgebrishvili G, Kolar Z and Bouchal J: Collagen triple helix repeat containing 1 protein, periostin and versican in primary and metastatic breast cancer: An immunohistochemical study. J Clin Pathol 64: 977-982, 2011.

53. Clezardin P and Teti A: Bone metastasis: Pathogenesis and therapeutic implications. Clin Exp Metastasis 24: 599-608, 2007.

54. Lv Y, Wang W, Jia WD, Sun QK, Huang M, Zhou HC, Xia HH, Liu WB, Chen H, Sun SN and Xu GL: High preoparative levels of serum periostin are associated with poor prognosis in patients with hepatocellular carcinoma after hepatectomy. Eur J Surg Oncol 39: 1129-1135, 2013.
55. Riener MO: Diagnosis of tumours of the liver and the biliary tract: New tissue and serum markers. Pathologe 32 (Suppl 2): S304-S309, 2011.

56. Bridgewater J, Galle PR, Khan SA, Llovet JM, Park JW, Patel T, Pawlik TM and Gores GJ: Guidelines for the diagnosis and management of intrahepatic cholangiocarcinoma. J Hepatol 60: 1268-1289, 2014.

57. Malaguarnera G, Paladina I, Giordano M, Malaguarnera M, Bertino G and Berretta M: Serum markers of intrahepatic cholangiocarcinoma. Dis Markers 34: 219-228, 2013.

58. Tamandl D, Herberger B, Gruenberger B, Puhalla H, Klinger M and Gruenberger T: Influence of hepatic resection margin on recurrence and survival in intrahepatic cholangiocarcinoma. Ann Surg Oncol 15: 2787-2794, 2008.

59. Bjornsson E, Kilander A and Olsson R: CA 19-9 and CEA are unreliable markers for cholangiocarcinoma in patients with primary sclerosing cholangitis. Liver 19: 501-508, 1999.

60. Sulpice L, Rayar M, Desille M, Turlin B, Fautrel A, Boucher E, Llamas-Gutierrez F, Meunier B, Boudjema K, Clément B and Coulouarn C: Molecular profiling of stroma identifies osteopontin as an independent predictor of poor prognosis in intrahepatic cholangiocarcinoma. Hepatology 58: 1992-2000, 2013. 